\title{
Ulcerative colitis treated by excision of the distal large bowel alone
}

\author{
G. NAKANO \\ M.D. \\ J. K. RITCHIE \\ D.M., M.R.C.P. \\ JAMES P. S. THOMSON \\ M.S., F.R.C.S. \\ St Mark's Hospital for Diseases of the Rectum and Colon, London EC1V 2PS
}

\begin{abstract}
Summary
Four patients with ulcerative colitis apparently limited to the rectum and distal sigmoid colon were treated by excision of the distal large bowel only, during the years 1964-1975 at St Mark's Hospital. Two patients have remained well since with no further treatment and the other two have had symptoms of colonic disease and have responded to medical measures.
\end{abstract}

KEY WORDS: proctitis, sulphasalazine.

The symptoms resulting from ulcerative colitis confined to the rectum and distal sigmoid colon are rarely severe enough to warrant surgical intervention. Medical measures, including intensive topical treatment almost always result in symptomatic relief, although a relapsing course is common. Should operation be required, it would appear that most surgeons prefer to carry out a proctocolectomy as there are only very few reports in the literature of disease limited to this site being treated by excision of the distal large bowel alone.

Between 1964 and 1975 at St Mark's Hospital, four patients with ulcerative colitis apparently limited to the rectum and distal sigmoid colon have been treated surgically by excision of the distal large bowel with a terminal sigmoid colostomy as the only operative procedure. Excluded from this number are 6 patients in whom only this part of the bowel was excised for dysplasia or carcinoma complicating colitis.

\section{Patients}

The clinical details of the four patients are shown in Table 1. The diagnosis was made on the basis of the history supplemented by sigmoidoscopic findings and proved by the appearances in rectal mucosal biopsies. Infective causes were excluded routinely. Radiological changes in the rectum were seen in all patients. All patients had been treated medically for prolonged periods with sulphasalazine, local steroids and, usually, courses of oral steroids. In cases 1 and $2_{\text {, }}$ these measures had been successful in bringing the symptoms under control for a time, but had nó prevented relapse, and surgical treatment appeared indicated in view of this and the length of history. I cases 3 and 4 with a shorter history, operation was advised as medical treatment had failed to control the distressing diarrhoea and urgency complicated, iㅡ. case 4 , by incontinence.

The operative specimens varied in length from 4 . to $54 \mathrm{~cm}$. All showed ulcerative colitis and in all cosses the inflammation was classified as severe in par the specimen. Taking the upper limit of the recturr $15 \mathrm{~cm}$, the inflammation extended into the sigmoid colon in all cases. The proximal margin of the specimen was involved in cases 1 and 2, but showe no evidence of inflammation in cases 3 and 4 where the extent of uninflamed mucosa was estimated at 19 $\mathrm{cm}$ and $9 \mathrm{~cm}$ respectively.

\section{Results}

Two patients have had no further trouble with colitis for intervals of 5 and 10 years. In two patien there has been evidence of colonic involvement. Thie first patient (case 3) was re-admitted 2 months afte rectal excision with loose colostomy actions and bleeding for 1 week. The passage of the sigmoido scope via the colostomy to $15 \mathrm{~cm}$ showed a granulaw mucosa. He was treated with sulphasalazine and has remained well since on this drug. Excision of $12 \mathrm{crm}$ of colon during reconstruction of the colostomy lid years postoperatively showed ulcerative colitis throughout the excised segment. A recent colono scopy showed the changes of ulcerative colitis in a sections from the ascending to the descending colof The second patient (case 4) was well for 4 yeas postoperatively on no treatment when he developed colostomy diarrhoea and bleeding, and sigmoido- 
TABLE 1. Clinical details of the four patients investigated

\begin{tabular}{cccccl}
\hline $\begin{array}{c}\text { Case } \\
\text { number }\end{array}$ & Sex & $\begin{array}{c}\text { Age at } \\
\text { operation } \\
\text { (years) }\end{array}$ & $\begin{array}{c}\text { Length of } \\
\text { history } \\
\text { (years) }\end{array}$ & $\begin{array}{c}\text { Course of } \\
\text { disease }\end{array}$ & Outcome \\
\hline 1 & F & 69 & 40 & Intermittent & Well 5 years after surgery \\
2 & M & 61 & 20 & $\begin{array}{c}\text { Intermittent } \\
\text { Continuous }\end{array}$ & $\begin{array}{l}\text { Well 10 years after surgery } \\
\text { Colonic disease 2 months after surgery. } \\
\text { Medical treatment given. } \\
\text { Well 13 years after surgery } \\
\text { Colonic disease 4 years after surgery. } \\
\text { Medical treatment given. } \\
\text { Well } 8 \text { years after surgery }\end{array}$ \\
\hline
\end{tabular}

scopy via the colostomy showed an abnormal mucosa with contact bleeding and mucopus. He was treated with sulphasalazine and a later biopsy showed the changes of colitis in a resolving phase. Admission was required a year later for relapse with loose colostomy actions and an instant colostomy enema showed involvement of the colon as far proximally as the hepatic flexure. He was treated with oral steroids and improved, and has remained well for the last 2 years on sulphasalazine only.

\section{Discussion}

In the absence of complications it seems that ulcerative colitis confined to the rectum (idiopathic proctitis) when normal mucosa can be seen in the rectum above the inflamed segment on sigmoidoscopy, requires surgery very rarely indeed. Watts, de Dombal and Goligher (1966) mentioned five patients with disease clinically confined to the rectum, of whom three were treated by rectal excision and a terminal left iliac colostomy, but in two of these patients there were complications present, carcinoma in one and severe sepsis in the other. Moreover, pathological examination of the specimen showed disease confined to the rectum in only two of the five patients. Clark and Ward (1980) give details of four patients with disease apparently confined to the rectum treated by excision of the distal large bowel alone. Histology showed inflammation at the proximal excision line in the sigmoid in all cases and three patients developed recurrent symptoms within a year.

Once the disease has involved the sigmoid colon, the probability of surgery has been estimated at $6 \pm 3 \%$ at 5 years from the onset of symptoms in one series (Ritchie, Powell-Tuck and Lennard-Jones, 1978) and, in these patients, always followed exten- sion of the disease. In the years 1964-75 at this hospital, only one patient of the 146 treated by one stage total proctocolectomy had disease confined to the distal colon.

One other point of interest arises as a result of a study of these patients. In cases 3 and 4 , the specimens showed normal mucosa at the proximal limit of excision. Nevertheless there is good clinical and histological evidence of ulcerative colitis in the more proximal colon subsequently.

The clinical course of the four patients reported here suggests that excision of the rectum and sigmoid colon may be an adequate operation for patients with distal ulcerative colitis in whom the symptoms are so incapacitating that surgery is indicated to enable them to return to a normal life. The fact that only five patients with distal disease (the four reported here and one treated by total proctocolectomy) have required surgery in the years 1964-75 at this hospital suggests that disease of this extent usually responds well to medical measures.

\section{Acknowledgments}

We thank the clinicians of St Mark's Hospital for permission to study the case notes of their patients.

We are grateful to Dr Basil C. Morson for reviewing the pathology:

\section{References}

Clark, C.G. \& W ARD, M.W.N. (1980) The place of isolated rectal excision in the treatment of ulcerative colitis. British Journal of Surgery, 67, 653.

Ritchie, J.K., POWELL-TUCK, J. \& LenNaRd-Jones, J.E. (1978) Clinical outcome of the first ten years of ulcerative colitis and proctitis. Lancet, i, 1140.

WATTS, J.MCK., DE DOMBAL, F.T. \& GoligheR, J.C. (1966) Early results of surgery for ulcerative colitis. British Journal of Surgery, 53, 1005. 